\begin{tabular}{|c|c|}
\hline 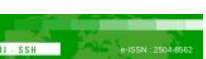 & Malaysian Journal of Social Sciences and Humanities (MJSSH) \\
\hline Malaysian Journal of & Volume 6, Issue 3, March 2021 \\
\hline (MJ-SSH) & e-ISSN : 2504-8562 \\
\hline & $\begin{array}{l}\text { Journal home page: } \\
\text { www.msocialsciences.com }\end{array}$ \\
\hline
\end{tabular}

\title{
Tahap Penggunaan dan Kefahaman Murid dalam Penggunaan Gabungan Pakej Bahan Bantu Mengajar Multimedia dalam Pengajaran dan Pembelajaran Sejarah
}

\author{
Sulaiman Sarabani1 \\ ${ }^{1}$ Fakulti Pendidikan, Universiti Kebangsaan Malaysia (UKM) \\ Correspondence: Sulaiman Sarabani (sulaimansarabani@ggmail.com)
}

\begin{abstract}
Abstrak
Kajian ini bertujuan untuk mengenal pasti tahap penggunaan dan tahap kefahaman murid dalam penggunaan gabungan pakej bahan bantu mengajar multimedia dalam pengajaran dan pembelajaran Sejarah. Pengajaran dan pembelajaran sejarah dewasa ini memerlukan inovasi dan kreativiti agar dapat membantu menaikkan pencapaian pelajar. Gabungan pakej multimedia diharap dapat mencapai tujuan untuk mendapatkan pengajaran dan pembelajaran yang lebih sistematik dan efisien. Responden kajian dan sampel kajian adalah seramai 66 orang murid tahun empat, tahun lima dan tahun enam di Sekolah Kebangsaan Biah Batu 65, Daerah Beaufort. Negeri Sabah. Responden yang dipilih seramai 66 orang murid daripada 88 populasi murid. Dapatan kajian mendapati bahawa tahap penggunaan gabungan pakej bahan bantu mengajar multimedia dalam pengajaran dan pembelajaran Sejarah adalah tinggi dan turut mempengaruhi tahap kefahaman murid dalam mata pelajaran Sejarah.
\end{abstract}

Kata kunci: pengajaran dan pembelajaran, multimedia, pendekatan kuantitatif

\section{The Level of Usage and Understanding of the Combination of Multimedia Teaching Aids Package in History Teaching and Leaning}

\begin{abstract}
This study aims to identify the level of use and level of understanding among students towards the application of a combination of multimedia teaching aids package in the teaching and learning of History. Teaching and learning history today requires innovation and creativity in order to help improve student achievement. The combination of multimedia packages is expected to achieve the goal of obtaining more systematic and efficient teaching and learning. The respondents and the study sample were 66 students in year four, year five and year six at SK Biah Batu 65, Beaufort District. Sabah state. The respondents were 66 students from 88 student populations. The findings of the study found that the level of use of a combination of multimedia teaching aids package in the teaching and learning of History is high and also affects the level of understanding of students in History subject.
\end{abstract}

Keywords: teaching and learning, multimedia, quantitative approaches, 


\section{Pengenalan}

Seiring dengan perkembangan teknologi, bidang pendidikan juga tidak terkecuali daripada menerima dan mengaplikasikan multimedia khususnya dalam proses pengajaran dan pembelajaran (PdP). Kini terdapat pelbagai bentuk multimedia yang sesuai diaplikasikan dalam proses pengajaran dan pembelajaran. Multimedia adalah sistem komunikasi interaktif berdasarkan teknologi komputer yang menggabungkan pelbagai unsur media seperti teks, audio, video, grafik dan animasi. Gabungan multimedia ini boleh didapati dalam perisian (software) seperti Microsoft Word, Powerpoint, Google form dan kuiz. Gabungan multimedia adalah integrasi atau gabungan kombinasi pelbagai jenis media yang berlainan iaitu grafik, animasi, teks, video, audio dalam satu sistem digital (Gayeki, 1993). Gabungan multimedia dalam komponen sistem komputer dapat memberikan kemudahan kepada pengguna untuk memahami sesuatu melalui teks, animasi, grafik, fotografik, video, gambar yang dipaparkan (Feldman, 1994).

Hari ini proses pembelajaran turut dibantu gadjet berasaskan komputer seperti telefon pintar dan tablet yang boleh melakukan operasi. Kehadiran teknologi ini pastinya boleh dimanfaatkan oleh guru kerana pelajar hari ini merupakan pelajar yang celik IT dan mereka pastinya akan mudah memahami pembelajaran yang menggunakan kaedah terkini. Melalui medium multimedia sebagai bahan bantu mengajar, guru boleh menggunakan beberapa aplikasi multimedia dalam satu-satu sesi pembelajaran dengan tujuan untuk meningkatkan minat pelajar dalam mendalami isi pembelajaran Sejarah kerana menurut Rusmiyati (2014), multimedia boleh memberi impak positif kepada pelajar khusus dalam pemahaman teks Sejarah. Malahan multimedia juga boleh membantu guru meningkatkan prestasi pelajar (Mahzan, 2016).

Aplikasi gabungan multimedia dalam bilik darjah turut mempengaruhi pencapaian akademik pelajar (Said et al., 2015). Hal ini kerana penggunaan multimedia bagai bahan bantu mengajar banyak memberi peluang kepada pelajar untuk mengawal pembelajaran dengan lebih baik sama ada secara berkumpulan, bersendirian atau interaktif (Khairuddin \& Mailok, 2020). Pelajar juga boleh menentukan masa, isi kandungan, iklim, cadangan aktiviti dan maklumat yang disukai berpandukan silibus bagi sesuatu mata pelajaran.

Penggunaan pelbagai bentuk multimedia diharap dapat membantu situasi ini. Di negara maju, pengajaran dan pembelajaran dengan menggunakan gabungan multimedia dan teknologi maklumat dan komunikasi (TMK) dapat menarik minat dan meningkatkan pencapaian pelajar sejarah (Lee, 2013). Perkembangan terkini menggunakan internat salah satu komponen multimedia yang penting menjadi inovasi penting dalam pengajaran dan pembelajaran. Malahan, penggunaan multimedia juga membantu merangsang pelbagai deria murid, malah akan membantu menarik minat pelajar sejarah dalam mempelajari sesuatu mata pelajaran (Jamalludin \& Zaidatun, 2003).

\section{Pernyataan Masalah}

Subjek sejarah telah dijadikan oleh kerajaan Malaysia sebagai syarat wajib lulus dalam Sijil Pelajaran Malaysia (SPM) mulai tahun 2013. Oleh itu kepentingan subjek sejarah di sekolah semakin meningkat. Pelajar perlu lulus subjek sejarah untuk mendapat Sijil Pelajaran Malaysia. Adalah menjadi tanggungjawab guru sejarah dari peringkat sekolah rendah dan sekolah menengah menyediakan aktiviti pengajaran dan pembelajaran sejarah yang berkualiti kepada pelajar. Aktiviti pengajaran dan pembelajaran yang terbaik untuk pelajar sejarah dapat dilaksanakan dengan peranan multimedia dengan penggunaan sebagai bahan bantu mengajar. Pengintegrasian teknologi internat dan gabungan multimedia akan memberi kesan yang positif kepada perkongsian maklumat.

Penggunaan pelbagai gabungan multimedia sebagai bahan bantu mengajar oleh guru dan pelajar dalam pengajaran dan pembelajaran adalah langkah kreatif seorang guru sejarah. Ini kerana menurut Mahzan et al. (2013), pengajaran dan pembelajaran sejarah yang tidak kreatif akan menimbulkan rasa bosan dan kurang minat pelajar. Menurut Abdul Rahim (1993), pelajar tidak berminat untuk mempelajari Sejarah 
kerana terdapat banyak fakta yang perlu dihafal. Manakala, Khoo (2001) telah melihat kegagalan Sejarah kerana tidak dapat mencapai objektifnya, ini disebabkan oleh fakta bahawa guru gagal memilih kaedah pengajaran yang sesuai dan ketidakmampuan mereka untuk mencipta pengalaman pembelajaran yang menyeronokkan. Malahan menurut Abdullah (1991), mata pelajaran Sejarah gagal mencipta pelajar yang menyedari dan menghayati nilai-nilai kebangsaan kerana terlalu menekankan pada peperiksaan (kognitif) dan tidak menghiraukan aspek afektif dalam pembelajaran. Di samping itu, Aziz Deraman (1994), menyatakan bahawa kegagalan Sejarah tidak dapat mengurangkan isu perkauman akibat kegagalan guru menyampaikan pelajaran melalui pendekatan yang berkesan.

Kaedah penyampaian yang kurang berkesan adalah kesilapan pertama dalam menguasai subjek sejarah (Brown, 1980). Menurut Bahari Md. Shah (2011), keberkesanan penyampaian pembelajaran oleh guru dipengaruhi oleh tahap kreativiti guru dalam menyampaikan ilmu sejarah dalam bilik darjah. Bagi menarik minat pelajar untuk mempelajari sejarah penggunaan multimedia sebagai teknik terbaharu dalam pengajaran dan pembelajaran sejarah adalah sangat perlu (Rosssaffrin \& Ahmad, 2007). Peranan multimedia untuk membantu guru untuk pengajaran dan pembelajaran Sejarah kerana multimedia mempunyai pelbagai bentuk dan beberapa fungsi serta peranan yang sesuai untuk pengajaran Sejarah. Multimedia akan membantu pelajar mendapat pelbagai maklumat hanya di hujung jari sahaja (Jamalludin \& Zaidatun, 2003). Sehubungan dengan itu, dalam kajian ini pengkaji akan mengenal pasti tahap penggunaan pelbagai gabungan multimedia yang digunakan oleh guru sebagai bahan bantu mengajar dalam mata pelajaran Sejarah dan kesannya ke atas kefahaman pelajar.

\section{Objektif Kajian}

Objektif kajian untuk mengenal pasti tahap penggunaan multimedia untuk pengajaran dan pembelajaran sejarah. Dalam konteks kajian ini mengenal pasti tahap kefahaman murid terhadap mata pelajaran Sejarah selepas penggunaan multimedia dalam pengajaran dan pembelajaran. Peserta kajian terdiri daripada pelajar seramai 66 orang peserta kajian. Soal selidik telah diedarkan bagi mengumpul data untuk mencapai objektif kajian ini iaitu :

i. Mengenal pasti tahap penggunaan gabungan multimedia dalam pengajaran dan pembelajaran Sejarah dalam kalangan pelajar.

ii. Mengenal pasti tahap Kefahaman pelajar dalam mata pelajaran Sejarah.

iii. Mengenal pasti hubungan tahap penggunaan gabungan multimedia dan tahap kefahaman murid dalam pengajaran dan pembelajaran Sejarah.

\section{Metod Kajian}

\section{Reka bentuk kajian}

Reka bentuk kajian ini berbentuk deskriptif bagi mengenal pasti dan mengkaji secara empirikal dan sistematik berkaitan tahap penggunaan dan tahap kefahaman gabungan pelbagai bahan bantu mengajar multimedia dan kesannya ke atas kefahaman pelajar. Kajian ini akan menggunakan reka bentuk kajian tinjauan. Menurut Mohd Majid (1998), kajian tinjauan merupakan salah satu jenis kajian dalam penyelidikan deskriptif. Menurut Creswell (2005) reka bentuk kajian tinjauan adalah prosedur dalam penyelidikan kuantitatif yang mana pengkaji menjalankan satu tinjauan terhadap sampel atau keseluruhan populasi. Dalam kajian ini, pengkaji memutuskan apa yang hendak dikaji, bertanya soalan yang khusus, mengecilkan skop soalan,mengumpulkan data daripada peserta, menganalisis nombornombor tersebut menggunakan statistik dan menjalankan inkuiri dalam bentuk objektif dan tidak bias (Cresswell, 2008). Kajian kuantitatif dikaitkan dengan data numerika dan ketepatan ,yang mana berdasarkan inkuiri positivis yang menggunakan kajian eksperimental dan data numerika untuk dianalisis dengan ujian statistik (Chua, 2006). 


\section{Populasi dan Sampel kajian}

Memandangkan kajian ini bertujuan untuk mengenal pasti tahap penggunaan dan tahap kefahaman multimedia dalam pembelajaran Sejarah, maka pengkaji telah memilih lokasi kajian di salah sebuah sekolah berdekatan dengan tempat tinggal pengkaji iaitu di Sekolah Kebangsaan Biah Batu 65, Daerah Beaufort Negeri Sabah. Dalam kajian ini, pengkaji telah menyasarkan murid tahap dua iaitu murid-murid Tahun 4, Tahun 5 dan Tahun 6. Keseluruhan populasi tahap dua di sekolah ini adalah seramai 88 orang. Pengkaji telah menggunakan kaedah persampelan berdasarkan jadual saiz persampelan Krejcie dan Morgan (1970). Oleh itu, seramai 66 orang responden akan terlibat dalam menjawab borang soal selidik.

\section{Instrumen Kajian}

Kaedah kuantitatif digunakan oleh pengkaji. Soal selidik sebagai instrumen kajian telah diedarkan kepada responden kajian bagi mendapatkan data dan pandangan murid tentang tahap penggunaan gabungan multimedia sebagai alat bantu mengajar guru dalam pembelajaran Sejarah. Satu set soal selidik yang terdiri daripada 23 item telah dikemukakan kepada responden untuk dilengkapkan. Item yang digunakan dalam soal selidik dibahagikan kepada tiga bahagian iaitu demografi, tahap penggunaan gabungan multimedia, tahap kefahaman murid dalam mata pelajaran Sejarah. Responden diberi tempoh 40 minit untuk menjawab soal selidik dan mereka mempunyai masa yang mencukupi untuk melengkapkan borang soal selidik tersebut. Set soalan dalam soal selidik ini terdiri dari tiga item aneka pilihan dan 20 soalan digubal dengan menggunakan 'Skala Likert' sebagai pilihan jawapan responden. Untuk skala likert, para responden hanya perlu menyatakan darjat persetujuan mereka dengan menandakan nombor pilihan mereka berdasarkan arahan dan keterangan skala yang dinyatakan pada awal set soal selidik. Penggunaan skala likert ini memudahkan responden memberikan respons mereka. Soal selidik juga memudahkan pengkaji mengkodkan data dan seterusnya menganalisis data tersebut.

\section{Dapatan Kajian}

\section{Latar belakang Demografi}

Latar belakang responden memperihalkan mengenai latar belakang 66 orang responden daripada kalangan murid tahap dua di Sekolah Kebangsaan Biah Batu 65, Daerah Beaufort Negeri Sabah. Data kajian ini telah dikumpulkan melalui soal selidik bersama 66 orang peserta sebagai peserta kajian. Berdasarkan data soal selidik didapati bahawa seramai 26 (39.4\%) murid lelaki terlibat dalam kajian ini dan murid perempuan pula diwakili seramai $40(60.6 \%)$ responden. Peserta kajian terdiri daripada pelbagai kaum iaitu $10(15.2 \%)$ murid berbangsa Bisaya, 20 (30.3\%) murid berbangsa Murut, 17 (25.7\%) murid berbangsa Dusun, dan selebihnya berbangsa Brunei iaitu seramai 19 responden (28.8\%). Kesemua murid juga mempunyai asas teknologi kerana pernah menggunakan perisian multimedia.

Jadual 1: Latar Belakang Demografi

\begin{tabular}{lcc}
\hline Kategori & $\begin{array}{c}\text { Kekerapan } \\
(\mathbf{n = 6 6 )}\end{array}$ & $\begin{array}{c}\text { Peratus } \\
(\boldsymbol{\%})\end{array}$ \\
\hline Jantina & 26 & 39.4 \\
Lelaki & 40 & 60.6 \\
Perempuan & & \\
Bangsa & & \\
Bisaya & 10 & 15.2 \\
Murut & 20 & 30.3 \\
Dusun & 17 & 25.7 \\
Brunei & 19 & 28.8 \\
Lain-lain & 0 & 0.0 \\
\hline
\end{tabular}




\section{Tahap Penggunaan Gabungan Multimedia}

Hasil kajian yang telah dijalankan untuk meninjau tahap penggunaan gabungan multimedia dalam kalangan murid dalam mata pelajaran Sejarah seperti jadual 2 di bawah. Secara keseluruhan daripada analisis data yang telah dijalankan menunjukkan tahap penggunaan adalah berada pada tahap yang tinggi iaitu seramai $40(60.6 \%)$ orang responden menyatakan tahap penggunaan multimedia mereka adalah tinggi. Manakala, seramai $24(36.4 \%)$ orang responden mengatakan bahawa tahap penggunaan mereka adalah berada pada tahap yang sederhana. Hanya 2 sahaja (3.0\%) orang responden yang menyatakan tahap penggunaan mereka adalah rendah. Ini menunjukkan bahawa tahap penggunaan gabungan multimedia dalam kalangan murid dalam mata pelajaran Sejarah di Sekolah Kebangsaan Biah Batu 65, Daerah Beaufort Negeri Sabah adalah pada tahap yang tinggi. Nilai min dan sisihan piawaian ialah $\mathrm{M}=3.49, \mathrm{SP}=.654$.

Jadual 2: Tahap Penggunaan Gabungan Multimedia

\begin{tabular}{lcccc}
\hline \multicolumn{1}{c}{ Tahap } & $\begin{array}{c}\text { Kekerapan } \\
(\mathbf{n = 6 6 )}\end{array}$ & $\begin{array}{c}\text { Peratusan } \\
(\mathbf{\%})\end{array}$ & Min & $\begin{array}{c}\text { Sisihan } \\
\text { Piawaian }\end{array}$ \\
\hline Rendah & 2 & 3.0 & 3.49 & .654 \\
Sederhana & 24 & 36.4 & & \\
Tinggi & 40 & 60.6 & & \\
\hline Jumlah & $\mathbf{6 6}$ & $\mathbf{1 0 0}$ & & \\
\hline
\end{tabular}

\section{Tahap Kefahaman Mata Pelajaran Sejarah}

Objektif kedua kajian ini adalah mengenal pasti tahap kefahaman dalam mata pelajaran Sejarah dalam kalangan murid tahap dua di Sekolah Kebangsaan Biah Batu 65, Daerah Beaufort Negeri Sabah. Hasil analisis data yang telah dijalankan, menunjukkan bahawa tahap kefahaman murid ini adalah berada pada tahap yang tinggi iaitu 34 (51.5\%). Hal ini menunjukkan bahawa tahap penggunaan multimedia telah mempengaruhi tahap kefahaman mereka dalam mata pelajaran Sejarah. Manakala, seramai 20 (30.3\%) orang responden menyatakan tahap kefahaman mereka pada kadar sederhana. Hanya 12 responden sahaja (18.2\%) responden yang menyatakan tahap kefahaman mereka terhadap mata pelajaran Sejarah berada pada tahap yang rendah. Ini dapat disimpulkan bahawa, tahap kefahaman mata pelajaran Sejarah selepas penggunaan multimedia sebagai alat bantu mengajar guru di bilik darjah adalah sederhana. Tahap penggunaan multimedia murid telah mempengaruhi kefahaman mereka yang tinggi dalam mata pelajaran Sejarah. Nilai min dan sisihan piawaian ialah $\mathrm{M}=3.42, \mathrm{SP}=.756$.

Jadual 3 : Tahap Kefahaman mata pelajaran Sejarah

\begin{tabular}{lcccc}
\hline \multicolumn{1}{c}{ Tahap } & $\begin{array}{c}\text { Kekerapan } \\
(\mathbf{n = 6 6})\end{array}$ & $\begin{array}{c}\text { Peratusan } \\
(\mathbf{\%})\end{array}$ & Min & $\begin{array}{c}\text { Sisihan } \\
\text { Piawaian }\end{array}$ \\
\hline Rendah & 12 & 18.2 & 3.42 & .756 \\
Sederhana & 20 & 30.3 & & \\
Tinggi & 34 & 51.5 & & \\
\hline Jumlah & $\mathbf{6 6}$ & $\mathbf{1 0 0}$ & & \\
\hline
\end{tabular}

\section{Hubungan Tahap Penggunaan Gabungan Multimedia dan Tahap Kefahaman Mata Pelajaran Sejarah}

Merujuk Jadual 4, dapatan dalam hubungan tahap penggunaan multimedia dan tahap kefahaman mata pelajaran Sejarah dalam kalangan murid di Sekolah Kebangsaan Biah Batu 65, Daerah Beaufort Negeri Sabah menunjukkan terdapat hubungan signifikan dengan nilai 0.001 iaitu $(r=.874,<0.005)$ yang membawa maksud bahawa kenaikan tahap penggunaan multimedia akan mengubah tahap kefahaman 
murid. Didapati juga terdapat hubungan positif antara kedua-dua pemboleh ubah ini yang membawa maksud bahawa, semakin tinggi tahap penggunaan multimedia, semakin tinggi kefahaman murid dalam pembelajaran Sejarah tahap dua di Sekolah Kebangsaan Biah Batu 65, Daerah Beaufort Negeri Sabah.

Jadual 4: Hubungan Antara Tahap Penggunaan dan Tahap Kefahaman

\begin{tabular}{llrr}
\hline & & \multicolumn{1}{c}{$\begin{array}{c}\text { Tahap } \\
\text { Penggunaan }\end{array}$} & $\begin{array}{c}\text { Tahap } \\
\text { Kefahaman }\end{array}$ \\
\hline Tahap Penggunaan & Pearson Correlation & 1 & $.874^{* *}$ \\
& Sig. (2-tailed) & 66 & .000 \\
Tahap Kefahaman & $\mathrm{N}$ & $.874^{* *}$ & 66 \\
& Pearson Correlation & .000 & 1 \\
& Sig. (2-tailed) & 66 & 66 \\
\hline **. Correlation is significant at the 0.01 level (2-tailed).
\end{tabular}

\section{Kesimpulan}

Rumusannya, penggunaan multimedia dalam proses pengajaran dan pembelajaran memberi banyak kebaikan kepada guru dan pelajar. Ini kerana kebanyakan murid telah mengetahui jenis-jenis perisian multimedia yang sesuai dalam pengajaran dan pembelajaran sejarah. Tugas mengajar guru sejarah akan lebih mudah dan aktiviti pengajaran dan pembelajaran yang lebih sistematik. Pelajar juga mendapat banyak kemudahan, contohnya pelajar boleh menyimpan data fakta sejarah menggunakan multimedia dan akan membukanya semula apabila diperlukan. Apa yang penting bahan bantu mengajar multimedia dapat menarik minat pelajar belajar sejarah. Keadaan ini seterusnya membolehkan pencapaian pelajaran sejarah pelajar berkembang. Kajian ini telah berjaya menunjukkan bahawa pencapaian pelajar sejarah akan meningkat dengan penggunaan medium multimedia dalam pengajaran dan pembelajaran sejarah. Pelajar akan mengalami kemajuan dalam mengikuti penilaian dengan multimedia. Syor pengkaji di masa hadapan agar pelajar dan guru menggunakan multimedia sebagai bahan bantu mengajar dalam pengajaran dan pengajaran sejarah agar dapat meningkatkan prestasi subjek sejarah.

\section{Rujukan}

Ahmad S.T \& Tamuri A.H. (2016). Persepsi Guru Terhadap penggunaan BBM berasaskan Teknologi Multimedia dalam pengajaran, hlm 52-62.

Akbariah Mohd Mahdzir. (2016). Kajian Pengukuran Tahap Perpaduan,hlm 13-19.

Rosli bin Ismail. (2017). Jurnal penyelidikan Pendidikan Jilid-18,hlm 2-272.

Irfan Naufal and Nurullizam Jamiat (2011). Pola Penyelidikan ICT Dalam Pendidikan Guru Di Malaysia : Analisis Prosiding Teknologi Pendidikan Malaysia.hlm 2-10.

Ida Rusmiyati , Joko Nurkamto, Samsi Haryanto. (2014). Penggunaan Multimedia Dalam Bahasa Sastera di SMP Negeri 2 Bawen Kabupaten Semarang, vol 2,hlm 179-181.

Lee Bih Ni. (2013). ICT Dan Pengajaran-Pembelajaran sejarah Di Sekolah, hlm.106-108.

Lezah @ Lejah Binti Kiamsin, Rusy Talin. (2018). Kaedah pengajaran yang diminati pelajar dan Justifikasinya,V. 3, hlm 138-143.

Mohd Mahzan Awang, Abdul Razaq Ahmad \& Nursyazwani Abdul Talib. (2016). Penggunaan multimedia dalam pendidikan sejarah abad ke-21 dan hubungannya dengan minat belajar sejarah, hlm 2-54.

Mohd Izham Mohd Hamzah \& Noraini Attan. (2007). Tahap Kesediaan Guru Sains Dalam Penggunaan Teknologi Maklumat Berasaskan Komputer Dalam Proses Pengajaran Dan Pembelajaran, hlm 4659. 
DOI: https://doi.org/10.47405/mjssh.v6i3.694

Nur Syazwani binti Abdul Talib, Kamarulzaman Abdul Ghani, Nur Azuki Yusoff , Mohd Mahzan Awang.(2016). Kaedah pembelajaran sejarah dengan mengambil kira minat dan peningkatan prestasi, hlm 1-8

Siti Zaharah Mohid, Roslinda Ramli, Khodijah Abdul Rahman, Nurul Nadhirah Shahabudin. (2018). Teknologi Multimedia Dalam Pendidikan Abad 21, hlm 2-6.

Wikipedia, ensiklopedia bebas(2018. https://ms.wikipedia.org/wiki/Multimedia. 